\title{
Clinico-pathological aspects of the neurosyphilitic psychoses
}

\author{
KENNETH DeWHURST \\ D.Phil. (Oxon)., D.P.M.
}

Research Psychiatrist, Littlemore Hospital, Oxford

\section{Summary}

(1) The immediate causes of death of eighteen patients with neurosyphilitic psychosis are analysed. There were five females and thirteen males. Their average age was 56 years, and the mean length of stay in a mental hospital was approximately $2 \frac{1}{2}$ years.

(2) Of the original ninety-one patients, twentyeight had malaria therapy. There was one death due to malaria therapy, giving a mortality rate of $3.6 \%$. It is concluded that the risk associated with malaria is too great and fever induced by bacterial pyrogens is safer and just as effective.

(3) The duration of mental symptoms before treatment was started is analysed. In one group there was a delay of between 1 and 4 years before treatment was given. In six patients the disease ran a rapidly fatal course in spite of adequate antibiotics. Combined treatment may be beneficial in such cases as fever facilitates the penetration of penicillin into the cerebrospinal fluid.

(4) Of the four cases that came to necropsy, only one had a full pathological and histological examination of the brain and meninges. Although these four patients had profound dementia and considerable deterioration of the personality only minimal neuropathological and histological changes were found. It would seem that the widespread use of antibiotics has modified the pathological and histological picture in neurosyphilis, corresponding to alterations recently reported in the clinical features of the disease.

(5) Such adverse presenting symptoms as epilepsy, and profound dementia associated with pupillary and reflex abnormalities, are discussed.

\section{Introduction}

In a previous paper, Dewhurst (1968) surveyed the natural history of the neurosyphilitic psychoses presenting between 1950 and 1965 by analysing the clinical histories of ninety-one patients whose illnesses necessitated their admission to hospital. Selection bias was avoided as only patients admitted to mental hospitals were included. In spite of the advanced state of the disease, nearly half were eventually discharged from hospital (44 or $48.3 \%)$. Twenty-seven patients $(29.7 \%)$ became chronic, two were transferred before treatment was started and the remaining eighteen died $(19.7 \%)$. The clinico-pathological findings of the deceased patients are analysed in this paper.

\section{Clinical features}

Mode of admission

Only two patients reached a mental hospital from general hospitals. The other sixteen were admitted directly to a mental hospital. The fact that they all had at least one adequate course of penicillin suggests a lengthy, unrecognized period of mental illness before admission.

\section{Neuro-psychiatric picture}

Five patients presented with taboparesis and the other thirteen were diagnosed as dementis paralytica. Six patients (one-third of this series) presented with epileptiform seizures. Only two patients had no neurological symptoms on admission. The most common neurological signs were pupillary abnormalities (twelve), reflex abnormalities (nine), ataxia (four), slurred speech (four), tabetic signs (three) and tremors (three).

In spite of cases with mixed features the presenting psychiatric syndromes can be classified into the following broad categories: schizophrenia-like psychoses (two), depression (five) and dementia (eleven). Five patients presenting with a depressive illness were given a varying number of ECTs (three to twenty) before the correct diagnosis was established.

\section{Immediate cause of death}

Bronchopneumonia or lobar pneumonia, nine. Myocardial degeneration, four.

Acute heart failure during malaria therapy, one. Congestive heart failure, one.

Asphyxia due to obstruction of trachea with polythene, one.

Uraemia, one.

Pulmonary oedema, one.

Total, eighteen. 
Effects of treatment

Amongst the original group of ninety-one patients, thirty-one had combined fever and penicillin therapy. Twenty-seven patients had malaria therapy combined with penicillin and three patients were given fever therapy induced by a bacterial pyrogen ('Pyrexal', the lipo-polysaccaride of $S$. abortus equi). One patient had malaria therapy which had to be discontinued 7 days after the first fever owing to a quartenary or double tertian causing serious physical deterioration. Some months later, this patient had penicillin combined with twelve fevers induced by Pyrexal. He was subsequently discharged, and able to earn his living in full time employment. No deaths were attributable to artificial fever therapy.

Eighteen patients who died were treated with penicillin and other antibiotics. There were no fatal Jarisch-Herxheimer reactions. Of the twenty-eight patients having malaria therapy combined with penicillin one death was directly attributable to malaria. This patient died from heart failure after the sixth rigor. Malaria therapy was considered in another five patients but withheld on account of their poor physical health. Five patients had courses of ECT ranging from three to twenty convulsions. One of them, who had two courses of ten ECTs, had no neurological signs on first admission.

\section{Duration of mental symptoms}

The duration of mental symptoms from the patients' first attendance at a mental hospital until death are listed below. Whenever known the duration of psychotic symptoms before admission are also included.

\begin{tabular}{|c|c|c|c|c|}
\hline Sex & $\begin{array}{l}\text { Age at } \\
\text { death } \\
\text { (years) }\end{array}$ & Hospital & $\begin{array}{l}\text { Period in } \\
\text { mental } \\
\text { hospital }\end{array}$ & $\begin{array}{l}\text { Duration of } \\
\text { symptoms prior to } \\
\text { admission }\end{array}$ \\
\hline $\mathbf{M}$ & 52 & L.M.H. & $2 \frac{1}{2}$ years & Indeterminate \\
\hline $\mathbf{M}$ & 36 & L.M.H. & 5 years & 4 years \\
\hline $\mathbf{M}$ & 75 & L.M.H. & 2 months & Indeterminate \\
\hline $\mathbf{M}$ & 65 & L.M.H. & 1 month & Indeterminate \\
\hline $\mathbf{F}$ & 62 & Fairmile & 7 years & 1 year \\
\hline $\mathbf{M}$ & 71 & Fairmile & 2 months & 3 weeks \\
\hline $\mathbf{M}$ & 61 & St Johns & 8 months & Approx. 12 months \\
\hline $\mathbf{F}$ & 45 & St Johns & 2 months & Indeterminate \\
\hline $\mathbf{M}$ & 65 & Northants & 12 months & 12 months \\
\hline $\mathbf{M}$ & 31 & Northants & 15 months & 1 month \\
\hline $\mathbf{M}$ & 62 & Northants & 12 months & 1 month \\
\hline $\mathbf{M}$ & 35 & Northants & 16 days & 2 days \\
\hline $\mathbf{M}$ & 52 & Northants & 5 weeks & 12 months \\
\hline $\mathbf{F}$ & 64 & Northants & 3 months & Indeterminate \\
\hline $\mathbf{M}$ & 66 & Northants & 8 months & 4 months \\
\hline $\mathbf{F}$ & 55 & Northants & 13 years & 2 weeks \\
\hline $\mathbf{M}$ & 54 & Northants & 13 years & Indeterminate \\
\hline $\mathbf{F}$ & 60 & Knowle & 12 months & 2 years \\
\hline
\end{tabular}

Of the eighteen deceased patients, five were females and thirteen males. Their ages at death ranged from 31 to 75 years with a mean of 56 years. Length of stay in a mental hospital (though not always continuous) ranged from 16 days to 13 years with a mean of about $2 \frac{1}{2}$ years.

\section{Fulminating cases}

In six patients the disease ran a rapidly fatal course in spite of adequate antibiotics and an inactive CSF picture. The duration of the illness and its treatment in these fulminating cases was as follows:

\begin{tabular}{ll}
\hline $\begin{array}{c}\text { Duration of } \\
\text { psychosis }\end{array}$ & \multicolumn{1}{c}{ Treatment } \\
\hline (1) 16 days & 10 mega-units penicillin \\
(2) 8 months & $\begin{array}{l}34 \text { mega-units penicillin, } 9 \text { g tetracyline, } \\
8 \mathrm{~g} \text { chloramphenicol, } 8 \mathrm{~g} \text { Ledermycin }\end{array}$ \\
(3) 3 months & $\begin{array}{l}15 \text { mega-units penicillin, six N.A.B. in- } \\
\text { jections }\end{array}$ \\
(4) 3 weeks & 10 mega-units penicillin \\
(5) 9 months & 20 mega-units penicillin \\
(6) 2 months & 14 mega-units penicillin \\
\hline
\end{tabular}

\section{Clinico-pathological findings}

Only four brains were examined at necropsy. Minimal pathological and histological changes were found, although these patients had been profoundly demented.

Case 1

A male aged 31 , who probably contracted syphilis 12 years before admission, had been psychotic for 16 months before he died in a state of profound dementia. Brain: macroscopic appearances; diffuse milky opacity of the piaarachnoid with an increase in the sub-arachnoid spaces especially over the frontal lobes. The sulci were widened, and on the cut surface of the brain, the cortical grey matter was thinned. No histological examination.

\section{Case 2}

A male, who died aged 65, was first admitted to a mental hospital with dementia paralytica 12 months earlier. In spite of repeated courses of penicillin his condition deteriorated and terminal epileptic fits developed. Brain: Meninges appeared normal. Weight normal (1450 g). The gyri appeared a little narrowed. Cut surface of the brain appeared normal. There was a slight degree of patchy granularity of the ependyma of the third and fourth ventricles. The lateral ventricles appeared normal. A slight degree of 
atheroma of cerebral arteries. No histological examination.

\section{Case 3}

A female aged 55 had first been treated in a mental hospital for taboparesis 13 years before her death. Between 1950 and 1963 she had eight courses of penicillin each of 10 mega-units, and one course of erythromycin. Brain: Meninges appeared normal. Fine granularity of ependyma of fourth ventricle. Rest of brain appeared normal. No histological examination.

\section{Case 4}

A male aged 36 was admitted to Littlemore Hospital on a section order on the 4 September 1956. Had worked as a shop assistant until he began to have difficulty with simple arithmetic and was sacked. Developed signs of dementia and irritability. First diagnosed as dementia paralytica, in February 1955, and had 15 mega-units of penicillin. On admission his behaviour was childish and he had marked dementia. Apart from sluggish reflexes there were no abnormalities of the CNS.

Investigations: 14 September 1956, CSF WR and Kahn, positive. Cells: 3 lymphocytes, protein $96 \mathrm{mg} / 100 \mathrm{ml}$. Lange 23331110000-0. 22 September 1956, CSF protein $85 \mathrm{mg} / 100 \mathrm{ml}$; cells, 2 lymphocytes, WR positive.

Treatment and course: On 15 September 1956, given another course of 15 mega-units of soluble penicillin. He became incontinent, more suspicious and aggressive. Very impulsive and tended to strip off his clothing in public.

9 January 1960: CSF cells nil, protein 100 $\mathrm{mg} / 100 \mathrm{ml}$. Pandy doubtful. Lange 00111111100 . WR Positive. Given penicillin 15 mega-units and potassium iodide. On 8 July 1960, stuffed polythene foam rubber down his throat and died of suffocation.

Necropsy: The brain weighed $1300 \mathrm{~g}$. Meninges appeared normal. No pathological changes were noted on external inspection.

Fixed brain. Vertex: Appearance normal apart from the slightly milky opacity of the leptomeninges and minimal vascular congestion. Gyri appear normal. Base: No abnormalities apart from slight thickening of arachnoid over interpenduncular fossa. Coronal sections: Show a mild asymmetrical dilation of the lateral ventricles. The cortical ribbon appears slightly thinner in the frontal and anterior parts of the temporal lobes, otherwise no abnormalities are seen in the cortex, white matter, basal ganglia or thalamus. The ependymal surface appears smooth throughout. Brain stem and cerebellum appear normal. Dura, cerebral nerve roots and cord all appear normal. Histology: Section shows an excess of fibrous and protoplasmic astrocytes and of microglial red cells in the cortex. No striking changes seen in the cerebrum, brain stem or cord. The meninges and vessels appear normal. Although some regions of cortex are thinner than normal there is no obvious laminar cell loss. The degree of subpial and subependymal gliosis is not outside normal limits. No sign of demyelination of white matter.

Conclusion. Minor changes in cerebral cortex. No clear evidence of neurosyphilis.

\section{Discussion}

The fact that one-third of the deceased patients developed epilepsy, whereas only $18 \%$ of the ninety-one patients in the whole series had fits, suggests that their onset indicates a worsening prognosis. Others have reported a higher inci- $c$ dence of epilepsy. Bruetsch (1959), for example, $\vec{\infty}$ noted convulsions, apoplectic phenomena or a $\%$ psychomotor epilepsy in $35-65 \%$ of cases; and $\infty$ Brain (1962) found that half of all patients with neurosyphilis develop fits.

The neuropsychiatric picture suggests tha patients presenting with dementia associated with pupillary and reflex abnormalities, ataxia of $\overline{7}$ slurred speech have a worse prognosis than those 믐 presenting with a psychosis and no neurologica sign.

Kinnier Wilson (1954) quotes case historie suggesting that trauma is thought to precipitate neurosyphilitic psychosis. Occasionally a gumma has developed at the site of head injury. On the other hand, there is no record of gunshot wounds precipitating cerebral syphilis. Although there is only a small number in this series there is a suggestion that electrical trauma in the form of ECT may accelerate the progression of neurosyphilitic psychosis. It is possible that ECT alters vascular permeability and allows spirochaetes and their toxins access to brain tissue. This study suggests that ECT should be given cautiously unless neurosyphilis has been eliminated from the diagnosis. Fever treatment in neurosyphilis is usually regarded as implying malaria therapy, although just as good results are obtained by using safer bacterial pyrogens. Indeed, it is doubtful whether the continued use of malaria is justified owing to its high mortality rate. Ferraro \& Fong (1927) found a mortality rate ranging from 2.5 to $33 \%$, with double figures predominating; and Dattner (1933), one of the most experienced physicians, reported a mortality rate of $11.6 \%$. Simpson, Kendall \& Rose (1942) give the following summary of mor- 
tality rates associated with various forms of fever treatment:

\begin{tabular}{lcc}
\hline & Malaria & Artificial fever \\
\hline Mild paresis & $4 \%$ & Nil \\
Intermediate paresis & $9 \cdot 4 \%$ & $6 \cdot 5 \%$ \\
Severe paresis & $25 \cdot 8 \%$ & $17 \cdot 9 \%$ \\
\hline
\end{tabular}

In the present series a mortality rate of $3.6 \%$ in twenty-eight patients having malaria therapy is low. Although the majority of patients with neurosyphilitic psychosis are successfully treated with penicillin alone, combined fever (using a bacterial pyrogen) may well be advantageous in those who continue to deteriorate. In the present series, for example, Case 4 might well have responded to combined treatment if this had been administered in the early stages of the illness.

Four patients had been mentally ill for 1 year ; another showed mental symptoms 2 and 4 years before admission. The delay in beginning treatment is an obvious factor tending to raise the mortality rate. On the other hand, in six patients the disease ran a rapidly fatal course in spite of adequate antibiotics. Although most cases of late neurosyphilis respond to penicillin, there are several reported treatment failures. After warning against the assumption that penicillin is just as effective in treating all cases of late syphilis as it is in early cases, Reynolds (1948) explained the failure of treatment in these terms:

(1) Drug resistant cases with failure to arrest the disease.

(2) Clinical progression despite treatment.

(3) Recurrence of syphilitic lesions after favourable initial response.

(4) Development of new lesions elsewhere.

An account of the progression of syphilis in spite of adequate penicillin is given by Birkett (1961). After a satisfactory initial response to penicillin a male aged 58 relapsed. He was given three subsequent courses of penicillin totalling 9, 10 and 12 mega-units. He developed mental symptoms. Finally, the disease was arrested when he was given penicillin combined with malaria therapy. Dewhurst (1963) reported three patients with neurosyphilitic psychosis in whom repeated courses of penicillin failed to prevent clinical deterioration. When combined fever (induced by Pyrexal) was given they all improved sufficiently to be discharged.

It would seem, therefore, that one type of neurosyphilis can most effectively be arrested by giving combined fever and penicillin therapy. Alternatively, the therapeutic benefit of fever in neurosyphilis may be due to the fact that it potentiates the action of penicillin. Dewhurst \& Todd (1965) have shown that fever significantly increases the penetration of penicillin across the blood-CSF barrier. The effectiveness of penicillin in the treatment of neurosyphilis depends, to some extent, on its concentration in the CSF. Some penicillin failures may be explained in terms of an almost impenetrable blood-CSF barrier to penicillin. In this series, some of the rapidly progressive cases may well have responded to combined fever and penicillin treatment.

It is regretted that of the four cases that came to necropsy only one (Case 4) had a full neuropathological examination. There are few reports on the histological picture of the brain in cases of neurosyphilitic psychosis since antibiotics have been commonly used. Their widespread use for treating intercurrent infections has altered the clinical picture in neurosyphilis. Joffe, Black \& Floyd (1968) reported seven unusual cases of neurosyphilis all of whom had been given penicillin, or other antibiotics, for minor ailments in complete ignorance of the underlying syphilitic process. This altered clinical picture of neurosyphilis was confirmed by Heathfield (1968) in another catchment area of comparable size. Similarly, antibiotics have probably modified the pathological and histological appearances of the brain and meninges in patients coming to necropsy. The classical pathological description of dementia paralytica given by Greenfield et al. (1961) portrays a shrunken brain with frontal and temporal atrophy, dilated ventricles, adherent pia-arachnoid and a coarse granular appearance around the third and fourth ventricles particularly near the foreamen of Munro.

The discrepancy between the states of severe dementia and minimal cerebral pathological changes has been noted by Gammon et al. (1955) in seven cases of neurosyphilis. One paretic, who died 3 weeks after starting treatment, showed a typical histological picture: the others had ganglion cell loss with minimal lymphocytic infiltration. These authors state that the diagnosis of neurosyphilis would have been in doubt but for the associated degeneration.

Gädeken (1951) failed to find any histological evidence of syphilitic infection in a paretic who came to necropsy 25 years after the onset of the disease. His only treatment consisted of five bouts of relapsing fever in 1920 . Five years later all serological reactions were negative. Simma (1951) examined the brains of nine paretics and found varying degrees of inflammatory reactions less marked in the frontal cortex than in other areas. There were some secondary degenerative changes 
in the oral, middle and posterior parts of the thalamus.

\section{Acknowledgments}

I am grateful to Dr R. W. Armstrong and Dr B. M. Mandelbrote, successively Physician Superintendents, Littlemore Hospital, Oxford; Dr D. J. Arkle, Medical Director, Fairmile Hospital, Wallingford; Dr A. J. Galbraith, Physician Superintendent, Knowle Hospital, Fareham; Dr A. N. Graham, Physician Superintendent, St Crispins Hospital, Northampton and Dr D. C. Watt, Medical Director, St John's Hospital, Stone, for permission to examine clinical records. I am particularly indebted to $\mathrm{Mr} \mathrm{W}$. H. Buckley and $\mathrm{Mr}$ Brown of the laboratory St Crispin's Hospital, Northampton; and Mr J. Law, Record Officer at the same hospital, who were most helpful in tracing case histories. I am also indebted to Mr W. J. Dudgeon, Records Officer, Littlemore Hospital, Oxford. Finally, I should like to thank Dr D. R. Oppenheimer, Neuropathologist, Radcliffe Infirmary, Oxford, for permission to publish the necropsy report on Case 4, and the Oxford Regional Hospital Board for defraying my expenses.

\section{References}

BIRKeTt, D.A. (1961) Neurosyphilis (General-Paresis). Report of a case of failure of penicillin treatment. Brit. $J$. Vener. Dis. 37, 202.

BraIN, Lord (1962) Diseases of the Nervous System, 6th edn. Oxford University Press, London.

BRUETSCH, W.L. (1959) American Handbook of Psychiatry (Ed. by Silvano Arieti), Chapter 50, Vol. 2, pp. 1003-1005. Basic Books, New York.

DATTNER, B. (1933) Moderne Therapie der Neurosyphilis mit Einschluss der punktionstechnik und Liquoruntersuchung. Vienna.
Dewhurst, K. (1963) The use of a bacterial pyrogen in the treatment of neurosyphilis. Psychiat. neurol. (Basel), 145, 18.

Dewhurst, K. (1968), The neurosyphilitic psychoses today: A survey of 91 cases. Brit. J. Psychiat. (In press).

Dewhurst, K. \& TodD, J. (1965) The effect of fever on the penetration of penicillin into the cerebrospinal fluid. Int. J. Neuropsychiat. 1, 257.

Ferraro, A \& Fong, T.C.C. (1927) Malaria treatment of general paresis. J. Nerv. ment. Dis. 65, 225.

GadeKen, R. (1951) Das Morphologische Bild einer Klinisch 'Geheilten Progressiven Paralyse 25 Jahre Nach der Floriden Erkankung', Dtsch. Z. Nervenheilk. 165, 482.

Gammon, G.D., Lewey, F.H., Villon, H., Schwarz, G. \& STOKes, J.H. (1955) Pathologic observations of penicillintreated neurosyphilis. Amer. J. Syph. 34, 227.

Greenfield, J.G., Blackwood, W., MCMenemy, W.H., Meyer, A. \& Norman, R.M. (1961) Neuropathology. Edward Arnold, London.

Heathfield, K.W.G. (1968) Neurosyphilis. Brit. med. J. i, 765 .

Joffe, R., Black, M.M. \& Floyd, M. (1968). Changing clinical picture of neurosyphilis. Report of seven unusual cases. Brit. med. J. i, 211.

KinNier Wilson, S.A. (1954) Neurology (Ed. by A. Ninian Bruce), 2nd edn, Vol. 1. Butterworths, London.

REYNOLDs, F.W. (1948) Treatment-failures following use of penicillin in late syphilis. Amer. J. Syph. 32, 233.

SıмmA, K. (1951) Thalamusveranlerungen bei progressive $\bar{O}$ paralyse. Monatsch. Fur. psych. Neurol. 297.

Simpson, W.M., Kendell, H.W. \& Rose, D.L. (1942) The treatment of syphilis with artificial fever combined with 0 chemo-therapy. A critical view. Suppl. No. 16 to Venereal Disease Information. Washington D.C. 